IJM

29,4

304

Received 19 January 2006

Revised 11 November 2007

Accepted 4 January 2008

\section{Offering choice in benefits: a new Dutch HRM arrangement}

\author{
Carlien Hillebrink
}

Utrecht School of Economics, Utrecht University, Utrecht, The Netherlands

Joop Schippers

Utrecht University, Utrecht, The Netherlands and Institute of Labour Studies

(OSA), Tilburg, The Netherlands

Anneke van Doorne-Huiskes

Department of Social Sciences, Utrecht University. Utrecht,

The Netherlands, and

Pascale Peters

Department of Business Administration, Radboud University,

Nijmegen, The Netherlands

\begin{abstract}
Purpose - The purpose of this study is to examine what kinds of Dutch organisations offer their employees a choice in the composition of their benefits with the aid of a theoretical model that incorporates insights from rational choice theory, the theory of institutional pressures and the bundles of human resource management (HRM) theory.

Design/methodology/approach - To test the theoretical model data were collected from nearly 600 Dutch organisations in the market sector. Multivariate binary logistic regression analyses were used to analyse these data.

Findings - The research showed that flexible benefit plans (FBPs) are widespread and show a considerable degree of consistency in the options they offer. FBPs are most likely to be offered by organisations that have freedom to manoeuvre in their benefits, that witness other organisations around them offering such arrangements, and that offer HRM policies and practices that are strongly focussed on the combination of work and family, and on flexibility in working arrangements.

Research limitations/implications - Attention to HRM policies in addition to a combination of rational choice and institutional theory proved valuable in explaining the uptake of a new arrangement, and this merits further exploration.

Practical implications - FPBs offer Dutch organisations the opportunity to give their employees more choice in the way they are paid, and to adjust this pay to their personal situation. Offering this choice fits in with a family-friendly HRM structure and increases flexibility for both parties.
\end{abstract}

Originality/value - The paper provides useful information on FBPs.

Keywords Flexible benefits, Organizational change, Human resource management, The Netherlands

Paper type Research paper

\section{Introduction}

International Journal of Manpower Vol. 29 No. 4,2008

pp. $304-322$

(C) Emerald Group Publishing Limited 0143-7720

DOI $10.1108 / 01437720810884737$
Flexible benefits[1] have been part of Dutch employment relations since the first flexible benefit plan (FPB) was introduced by an American firm (Dow) in The Netherlands in 1983. By the turn of the millennium they appeared to have become fairly widespread (Hillebrink et al., 2004). Yet little is known about the kind of 
organisations that have introduced flexibility in their benefits, nor about their motivations for doing so. In this paper we examine what kind of organisations have chosen for such an arrangement, in order to explore the usefulness of flexible benefits for organisations and to shed greater light on the dispersion of new human resource management (HRM) arrangements amongst organisations. We do this with the aid of a theoretical model that incorporates the rational choice perspective, the theory of institutional pressures, and the bundles of HRM approach. Using this combination of theories enables us to focus on the various motivations organisations may have for introducing flexible benefits.

For 85 per cent of Dutch employees, labour relations are regulated by a collective labour agreement (CLA), either on industry or on company level (StvA, 2004). In the last decade these collective agreements have become increasingly flexible, giving both employers and employees greater room for manoeuvre (van Sas, forthcoming). The introduction of flexible benefit schemes is one of the forms this increased flexibility has taken.

With the introduction of choice in benefit packages, Dutch employers hope to become more attractive to employees, both present and future. By allowing employees to choose the benefits they prefer, organisations expect to offer a more valuable reward to their employees while keeping the costs under control. This way, organisations also hope to increase benefit efficiency, though empirical evidence to support these expectations is lacking.

Today, a considerable number of both industry and firm CLAs include an FBP. A review of industry CLAs in 2003 showed that 58 per cent of these agreements allowed employees some choice in their benefits (Schrama and van den Ameele, 2004). Korteweg et al. (2003) analysed the collective labour agreements in the database of the FNV, the largest trade union federation in The Netherlands. Of the 1,078 CLAs in this database, 17 per cent contained arrangements for selling and buying time off. These agreements covered at least 32 per cent of Dutch employees. As we discuss further on, we expect FBPs to be more common in organisations that are not covered by an industry agreement. In an annual survey for a popular magazine among 132, large Dutch organisations in 2004, 80 per cent of the organisations offered flexible benefits (Kuiper, 2004). Although this last survey only provides anecdotal evidence, it does give some indication of the spread of FBPs amongst larger organisations.

Despite their American roots, Dutch FBPs differ substantially from their American counterparts (Barringer and Milkovich, 1998). Health insurance benefits, the core of American FPBs, are not involved in the trades that Dutch employees can make, because the Netherlands has a collective health insurance arrangement. The trades that Dutch employees can make in their FBPs centre on the choice between time and money. Common options are trading in days of annual leave for extra pension, or trading in part of their wages for extra time off.

Dutch FBPs often take the form of a menu where employees can choose to trade in source benefits for goal benefits. The organisation defines the sources and goals that employees can choose to trade in against each other, and the constraints within which these trades can be made, including the exchange rate. For instance, an employee may choose to trade in annual leave for a higher pension contribution, but the organisation may limit this transaction to a certain number of days. Alternatively, if someone wishes to buy extra leave this may also be limited, to ten extra days per year for
Offering choice in benefits

305 
IJM

29,4

306 instance. Plans in which employees choose between pre-set packages and total remuneration models exist, but are far less common (Hewitt, Heijnis en Koelman, 2003).

Research into employee behaviour in FBPs shows that participation varies substantially between organisations, but seems to average around a quarter to a third of employees. People who change their benefits often trade in leave, for money or a new $\mathrm{PC}$, although the tax arrangement that made the latter trade interesting was cancelled in 2004. What the effect of this has been on both participation and the way people use their FBP remains to be seen (Delsen et al., 2006; Hillebrink, 2006; van Sloten et al., 2005; Hillebrink et al., 2004; Langedijk, 2001).

FBPs can take on many different forms, not just in the way they arrange choices, but also in the nature and extent of the trades in benefits they allow. Sometimes any form of choice is called an FBP, other times only extremely elaborate plans are qualified as such. For this study we use the following definition of an FBP:

A benefit plan in which employees can temporarily change the composition of their benefits, and can trade in money for time off and vice versa.

With this definition we separate very limited plans that only allow a single choice, from the more elaborate plans, which give employees more options. We introduce the time and money criteria to identify the plans that allow employees to make fundamental changes to their benefits, trading in benefits of a different nature.

In this paper we research what kinds of organisations have chosen for an $\mathrm{FBP}$ [2]. We do this based on information provided by 585 larger Dutch organisations $(>99$ employees) in the market sector. Previously, the introduction of new HRM arrangements in organisations has been studied with the aid of a rational choice approach to the organisation, and with models that stress the institutional pressures on organisations. In recent studies, these two approaches have been combined, and produced interesting results. Here we study the occurrence of FBPs in Dutch organisations with such a model incorporating both approaches, but introduce a third line of thought to this, that of bundles of HRM. We expect that including this focus on the inside of the organisation will enhance our understanding of which organisations have chosen for this arrangement.

Data for this research were collected in cooperation with two other research projects, that focussed on teleworking (Peters and Batenburg, 2004) and working times preferences (Baaijens, 2006). In this, it forms a part of a research approach that looks at goal-oriented organisational behaviour in a changing institutional context (see den Dulk, 2001; Remery, 1998).

\section{Theory}

For the foundation of our theoretical model, we approach the introduction of FBPs as an example of rational choice: for some organisations, working under certain conditions, the introduction of an FBP may be a useful choice, which will help them to achieve (more of) their goals. For other organisations, facing different conditions, an FBP may not be a useful choice at all, and these organisations will then abstain from introducing one (van der Burg et al., 1989). From this perspective, organisations contemplating the introduction of flexible benefits are presumed to take matters into consideration that are related to the characteristics and the situation of their organisation, and the goals they wish to achieve. Although these goals may be varied, 
organisations are expected to strive for a positive balance between costs and benefits. We expect that the factors taken into consideration can be divided into three groups: business considerations, institutional pressures, and HRM policies.

\section{Business considerations}

FBPs can be introduced to increase the usefulness, or efficiency of the benefits an organisation offers its employees. It can enhance the efficiency of their benefit plan because of the possible difference in value employer and employees can attach to a particular benefit. In this way, FBPs can be a relatively cheap way to increase the perceived value of pay for employees. This perceived value of pay is the value the compensation has to the employee. It is a representation of how well they think they are getting paid, overall, in terms of cash, but also in terms of benefits, and career prospects (Langedijk, 2001). The perceived value of a given benefit package is not the same for all employees, because it depends on the goals it enables them to achieve, and these vary with individual preferences and constraints. The value people attach to a generous parental leave arrangement will naturally depend on their family situation, just as the value people attach to pension plans (rightly or wrongly) depends on their age. By allowing employees to choose the benefit package they prefer, the value attached to this package as perceived by employees can increase. In principle, at least, the costs for the organisation could stay the same, as benefits are traded in as well.

Diversity plays an increasingly large role in organisations, where awareness of the variety that exists in staff composition has grown considerably, along with an appreciation for the benefits this can bring an organisation (Konrad et al., 2006; Kirton and Greene, 2005). Organisations with a very diverse employee population may find FBPs a particularly useful way to reward their employees. When there is a great deal of variation amongst the benefits employees desire, offering a benefit plan that is of equal value to all employees can be difficult. In an FBP, however, more employees will be able to choose a compensation that is useful for them. The more diverse an employee population, the more incentive there is for an organisation to let employees choose the benefits they prefer, instead of attempting to find a standard package that is of greatest value to most employees. We therefore expect that organisations with a very uniform employee population are less likely to choose for an FBP than organisations with a very diverse employee population.

Leave reservoirs may also make flexible benefits a more efficient way of paying. In recent years, Dutch organisations have started to become concerned with the leave reservoirs that some of their employees have been building up. Since 2000, employees have been able to save their unused vacation days for five years running, instead of one (Staatscourant, 2000). At the same time, increased economic growth combined with a tight labour market led to people taking relatively little leave (Korteweg et al., 2003). This has led to situations where people sometimes have so much leave stacked up that they are entitled to a break lasting months. The option an FBP offers of trading superfluous leave in for another benefit can make it a particularly attractive concept in these situations. Employees who do not take much time off will get to choose a set of benefits that suits them better, increasing their benefit satisfaction, while the risk for the organisation decreases. Therefore, we expect that it will be more attractive for organisations in which more employees have leave reservoirs to offer FBPs.
Offering choice in benefits 
IJM

29,4

308
Institutional surroundings

There is a school of thought that claims that organisations do not adopt new practices just out of "economic" considerations. DiMaggio and Powell (1983, p. 147) observed that:

structural change in organizations seems less and less driven by competition or by the need for efficiency. Instead [... ] bureaucratization and other forms of organizational change occur as the result of processes that make organizations more similar without necessarily making them more efficient.

The theory of institutional pressures proposes that institutional surroundings and pressures play a considerable role in these processes (Tolbert and Zucker, 1983; Meyer and Rowan, 1977). In the development of this theory over the decades, the notion of institutions has taken on a wider meaning. Where institutions classically refer to forces that explicitly and directly affect organisational behaviour, such as laws, in recent years more indirect sources of pressure have been incorporated into the concept. Scott (2001) separates institutional pressures in three pillars: regulative, normative and cultural-cognitive. Organisations have been shown to take institutional surroundings into consideration, in particular when it comes to their HRM policies (e.g. den Dulk, 2001; Ingram and Simons, 1995). We expect that there will be two elements of the institutional surroundings of an organisation relevant here: collective labour agreements, and the behaviour of other organisations.

The type of labour agreement organisations have with their employees affects various aspects of how organisations reward their employees. As said, the majority of Dutch employees are covered by some form of collective labour agreement (see the first section). This can take two different shapes, a CLA can be a source of pressure on an organisation to implement flexible benefits, but it can also exert pressure not to do this.

CLAs can be a direct source of institutional pressure when they prescribe flexible benefits to an entire industry (Benders et al., 2006). This can result in organisations introducing FBPs not because they think this will improve the functioning of the organisation, but only to meet the requirements their CLA puts on them. However, CLA sections on FBPs are often optional. A first exploration of the nature of FBPs in industry CLAs revealed that only 5 per cent of 370 organisations working under an industry CLA faced an outright obligation to introduce an FBP (Hillebrink, 2006). The majority of industry CLAs that include a paragraph on flexible benefits left the choice to the individual organisation. The direct pressure to introduce FBPs therefore seems limited.

The opposite pressure may be just as strong, or stronger. CLAs can be very specific and detailed on the point of benefits. As a result, while not actually prohibiting it, a CLA can make it very difficult for an organisation to implement an FBP independently. One of the reasons why CLAs may restrict in this way is a result of the opinion of unions. While unions have become more enthusiastic about flexible benefits in recent years, the largest Dutch union FNV Bondgenoten will only agree to a flexible benefit plan if the labour relations in the particular industry or organisation are good, which will also affect the occurrence of FBPs across industries (Hillebrink et al., 2004). For this reason we expect FBPs to be more prevalent among organisations that have their own CLA, as they have more room for manoeuvre than organisations that fall under an industry CLA. 
A second source of institutional pressure can come from other organisations. If many other organisations in a field offer their employees flexible benefits, an organisation may choose to introduce an FBP, even though this may not enhance organisational effectiveness in strict economic terms. This is an example of what DiMaggio and Powell (1983) call mimetic isomorphism. The mimicking of other organisations' behaviour will be considered to improve the legitimacy and status of an organisation. Also, competition on the labour market may make an organisation wish to keep up with the Joneses, so to speak. Organisations may look around them to keep abreast of what it entails to be a good employer. If they see many organisations that they consider to be similar offering FBPs, the will be more likely to choose for an FBP themselves than if they see relatively few FBPs around them.

\section{Bundles of HRM}

Following Oliver (1991) rational choice and institutional theory have been combined to study the occurrence of work-family arrangements in organisations (Goodstein, 1994; Ingram and Simons, 1995; den Dulk, 2001). Combining insights from these theories proved to be useful in explaining the introduction of these new HRM arrangements in organisations, and should also prove valuable in studying the occurrence of FBPs in organisations, as Barringer and Milkovich (1998) have illustrated on a theoretical level. den Dulk (2001) showed that institutional pressures can be incorporated in a model that retains the organisation as the central actor, deciding their actions based on the costs and benefits on factors from both areas. However, such a two-way model still does not look very deeply into the organisation. Although Oliver (1991) separated various ways in which organisations might respond to institutional pressures, these have been given relatively little attention in the empirical application of this fused theory so far.

For the third part of our model, we therefore turn to a different theory, the theory of bundles of HRM. We expect this theory to be a useful addition to our model because it incorporates the general approach an organisation takes to its employees, which may influence how they judge the usefulness of flexible benefits.

The theory of bundles of HRM, or complementarity of HRM, proposes that a consistent approach to employees increases the usefulness of separate arrangements (Baron and Kreps, 1999; Laursen and Mahnke, 2001). For instance, introducing teamwork but not some devolution of control may reduce the usefulness of teamwork as a practice. It may be technically beneficial to offer arrangements that strive for the same effect, but it will also help to send a clearer and therefore more effective message to employees. If all the different arrangements and policies point in the same direction, employees will get a clearer understanding of how the organisation views the employment relationship, and what it expects of them in return, and they can adjust their behaviour accordingly. Clearly, external effects can complicate such striving for consistency. In this approach, HRM policies are driven partly by the same factors as the introduction of an FBP. Analytically this presents certain complications, because some of these factors are endogenous, and others are not. We will return to this further on.

Baron and Kreps (1999) also point out that in similar situations radically different approaches to HRM can be effective: there is not always a universal best for a specific situation. The existing HRM context may affect the utility of newly introduced
Offering choice in benefits

309 
IJM

29,4

310

arrangements. Consistency may be more important than the particular approach taken, and path dependency plays its part.

FBPs may be seen as complementing HRM policies, but they can also be used as a substitute to such policies. An FBP gives an employer the opportunity to offer a wide array of choice to their employees in one arrangement, and do this instead of offering many separate arrangements, and organisations may choose to spend their HRM budget on the former rather than on the latter. If FBPs are complementary, then the introduction of an FBP will not replace existing HRM arrangements. If we find a positive link between certain HRM policies and the occurrence of FBPs in our model, this will support the complementarity hypothesis, whereas a negative effect will show that there is a substitution effect at play.

We expect FBPs to be related, be it through complementarity or substitution, to HRM arrangements that offer employees a certain degree of choice and variability, specifically in terms of pay, or in terms of other elements of the job, and to policies focussed on facilitating the combination of work and care.

In terms of pay, an FBP can be seen in two different lights: that of extras to the standard compensation, and that of variable pay. An FBP can offer many extra options to one's pay, and in this sense it can be an addition to an HRM structure already offering a wide variety of choice, or it can be a substitution for such extra's. FBPs bring some degree of variability to employees' pay. While the overall value to the organisation remains the same, the fact that employees may choose individual variations in their composition results in internal variability. Organisations that offer other variable pay arrangements such as group bonuses or stock options may choose for an FBP as an additional tool to increase this variability and flexibility, or introduce it instead of such variability.

A third bundle of HRM practices that can be taken into consideration relates to control. Flexible benefits affect the degree of choice employees get over the balance between their working and non-working time, and the freedom they have in making their own choices in this. Organisations that already offer their employees a certain degree of control over the fringe arrangements of their job may be less hesitant to introduce of flexible benefits, since they are less likely to see this as a dangerous reduction of control over their employees. So from a complementarity point of view, we expect FBPs to occur more often in organisations that offer their employees such self-control over various elements of their job construct, particularly in terms of time and location. The substitution hypothesis would here suggest that FBPs are introduced instead of such policies, to achieve the same effect.

The final bundle that may play a role is that of work-family HRM. FBPs have been presented as particularly useful for employees who combine work and care (StvA, 1999). Employers who make an effort to provide their employees a helping hand with their combination of work and care, with childcare arrangements and extensions to the leave arrangements in the Work Care Act (van Drongelen, 2002) may offer their employees a choice in their benefits more often too. Here too, an FBP can be introduced as a complement to existing structures, or as a substitute.

Figure 1 contains a schematic representation of the theoretical model developed for this study. The overall model rests strongly on the notion of the organisation as the central actor, taking factors of all three sections of the model into consideration when 


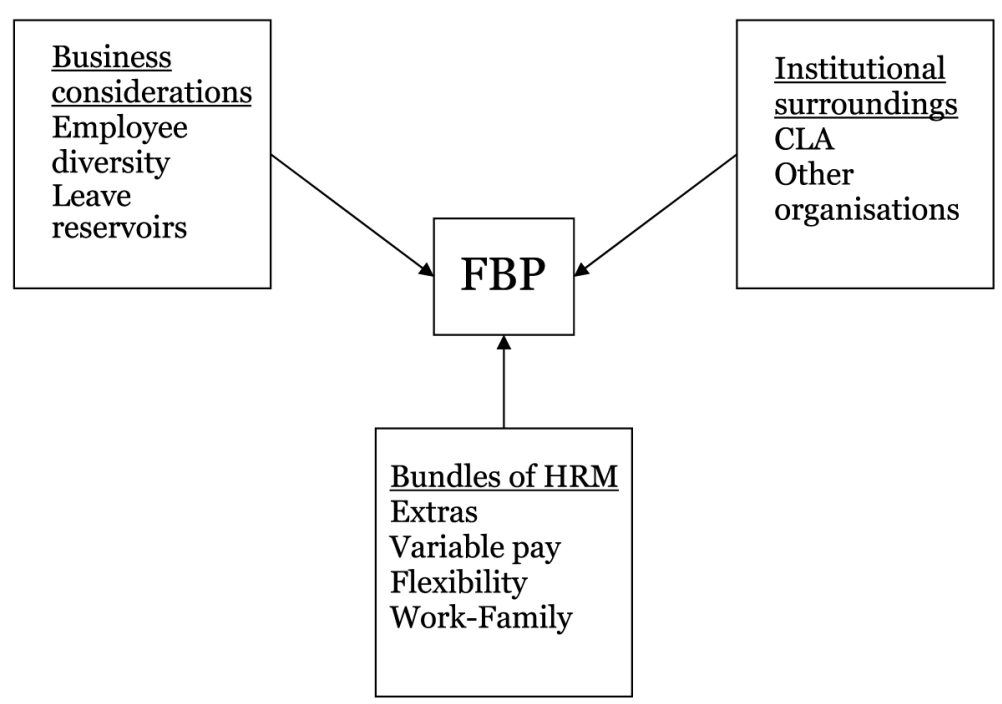

\section{Offering choice in benefits}

311

Figure 1.

Schematic representation of the theoretical model

deciding whether introducing a flexible benefit plan would help achieve the goals it strives for.

\section{Data and method}

Data for this study were collected with the use of an anonymous written questionnaire. We selected the addresses of Dutch organisations in the private sector with 100 employees or more from the Dutch Chamber of Commerce database. Organisations with few employees will find an FBP highly impractical and very expensive, so in order to get a statistically acceptable number of organisations only medium-sized and large organisations were approached.

In the spring of 2003, 2,927 questionnaires were sent out. After three weeks all organisations received a letter to thank people for taking the time to fill out the questionnaire, or, if they had not done so yet, to ask them again to do so (another questionnaire was included).

A total of 56 questionnaires were returned because the address was incorrect. So in effect, 2,871 questionnaires had been sent of which 606 were filled out and sent back. Two of these were doubles and we removed the second reply from our data. This left 604 questionnaires, and a response rate of 21 per cent. A similar approach a year earlier had resulted in a response rate of 28 per cent (Remery et al., 2003). The main reason for the lower response will be the developments in the Dutch economy at the time. The questionnaires were sent out at the beginning of a downturn in the Dutch economy. After years in which the labour market had been very tight, unemployment was rising and organisations were more likely to be letting employees go than having trouble attracting staff. These developments naturally reduced the interest among employers in issues such as elaborate employee benefits, and will in all likelihood have lead to a lower response rate.

Despite our intention to approach organisations with 100 employees or more, some smaller organisations did reply to our questionnaire. Changes such as in organisational 
IJM

29,4

312

size are not always updated regularly by organisations to the Chamber of Commerce. For this study, the organisations with less than 100 employees were removed from the dataset, leaving 585 cases.

The response came predominantly from organisations in manufacturing, the building industry and commercial services. Organisations in the manufacturing and building industries are over-represented in the survey compared to the Dutch economy as a whole. Of the organisations in the survey, 35.6 per cent were in the manufacturing industry, compared to 24.5 per cent of organisations in the Dutch market sector as a whole (with more than 100 employees). For the building industry this difference is smaller: 10.5 per cent in the survey, compared to 7.1 per cent in all Dutch organisations. The representation of organisations in the commercial services (18.1 per cent of responding organisations) is close to the national figure (18.5 per cent). A thorough analysis of the non-response is not possible, as we chose for an anonymous questionnaire, to improve the response.

\section{Variables}

Not everyone defines an FBP in the same way. To apply our definition of an FBP (as mentioned earlier), we asked whether organisations offered, and then what sources and goals employees could choose. Organisations were coded as having an FBP if they offered their employees choice in their benefits, and time and money were included as source and goal.

Organisations were asked to describe their employee population in terms of gender, educational level, age and the part-time/full-time ratio, expressed in percentages. Based on this, we developed a measure for the degree of uniformity in the employee population[3]. We constructed four measures of uniformity (on gender, age, education and part-time/full-time), by calculating the difference between the actual percentages given and maximal possible diversity. On this scale an organisation employing only men scores 50 points on uniformity, where an organisation employing 45 per cent men and 55 per cent women scores five points. For the three-category variables (education and age) the three (absolute) distances to 33 were added together and divided by three, so that an organisation employing 50 per cent lower educated and 50 per cent higher educated scores $(17+33+17 / 3) 22.3$ points, and an organisation employing equal groups of each scores zero points. A scale of overall diversity was constructed by adding the four scores together and dividing them by four. While there are undoubtedly many aspects of employee diversity that we could not include in our analyses, the main terms in which Dutch employees vary, relevant here, have been incorporated.

This measure of uniformity gives a good indication of the composition of the employee population. It shows the size of variation rather than the presence of a particular group. For the level of diversity amongst employees, the subject of our hypothesis, the degree of variation is more important than the presence of particular groups in significant numbers, so using the percentage of higher educated or the percentage of female employees for this purpose will give a far less distinct picture. In this uniformity measure, an organisation that consists purely of female employees is given the same score as an organisation that employs only men. And purely in terms of diversity these two are equal.

Organisations were asked whether there were many employees with a leave reservoir in their organisation, where the judgement of what constituted "many" was 
left to the respondent. This measure should therefore be taken as a representation of the perception of the organisation, indicating whether they feel there are many leave reservoirs or not. This was recoded into a dummy variable, with one representing those organisations where some or most employees have leave reservoirs and zero representing those in which leave reservoirs are very rare or non-existent.

Organisations were asked whether their employees worked under a CLA. This was recoded into a dummy variable coded one for organisations that had their own labour agreement and zero for organisations that were entirely covered by an industry CLA. Many organisations reported that part of their employees were covered by one, another part by another CLA. If only part of the employees were covered by a labour agreement that the organisation itself drew up, it was coded one.

Organisations were also asked whether they were aware of organisations similar to themselves offering FBPs. The answer categories were: no idea, and five indications of the dispersion ranging from almost none to almost all. This was recoded into two variables. First, a dummy variable for whether or not they were aware of other organisations offering FBPs, and second, a five-scale ordinal variable for the prevalence of other organisations offering an FBP.

The questionnaire asked organisations to indicate what other HRM arrangements they offered their employees, in terms of pay, leave arrangements, and flexibility. These were recoded into four variables, counting the number of variable pay arrangements (bonuses, performance pay, overtime compensations, stock options), extra pay options (saving arrangements, insurances, phones, cars, bicycles, PCs), work-family arrangements (paternity leave, childcare, emergency and care leave, extended maternity, adoption, sabbatical and parental leave), and flexible work arrangements (flexi-time, teleworking, compressed working week). For bivariate relations between these arrangements and the occurrence of flexible benefit plans, see Hillebrink (2006)[4].

As controlling variables we included organisational size (the number of employees on the payroll), and industry. Organisations were asked to tick the industry in which their primary activities lay. For the purpose of the analyses industries were bundled. We chose to do so to reduce the number of independent variables, and because the response varied considerably between industries. Retail, building and transport were combined into one dummy variable, as were the service industries (see Table I). We constructed a third dummy variable for the remaining industries.

To test the theoretical model we performed multivariate binary logistic regression analysis. A binary logistic regression calculates so-called odds ratios for dependent variables that have only two possible scores: zero or one. The odds ratio indicates by how much the odds that this variable is one increase with an increase of one unit in the given independent variable. Say that the odds ratio for organisational size is 1.500 , then every extra employee with which the organisation grows, increases the odds of that organisation has an FBP by 1.5. Were the odds ratio smaller than one, 0.800 for instance, the odds of an FBP would decrease the bigger an organisation.

\section{Results}

Of the 585 respondents, 251 (43 per cent) said the organisation they represented offered flexible benefits. In 88 per cent of these cases, all employees could change their benefits. Where only a part of the employees could do so, this was mostly caused by the fact that employees were covered by different CLAs. In a few cases
Offering choice in benefits

313 
IJM
29,4

314

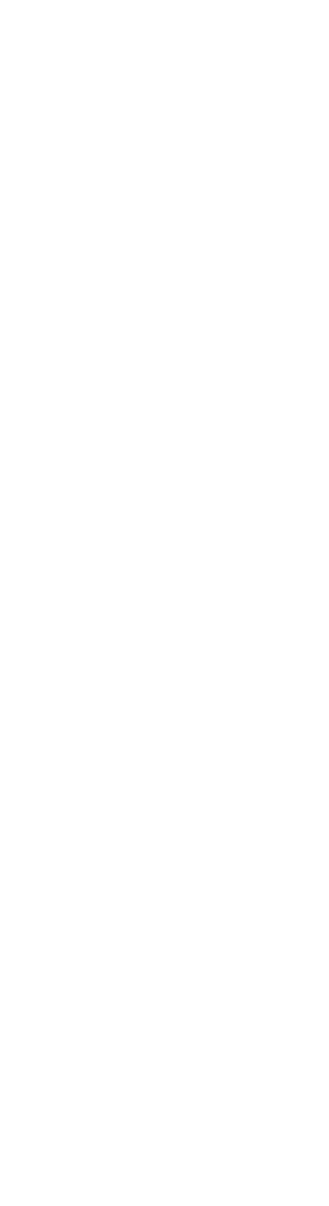

Table I.

Correlations between variables included in the analysis

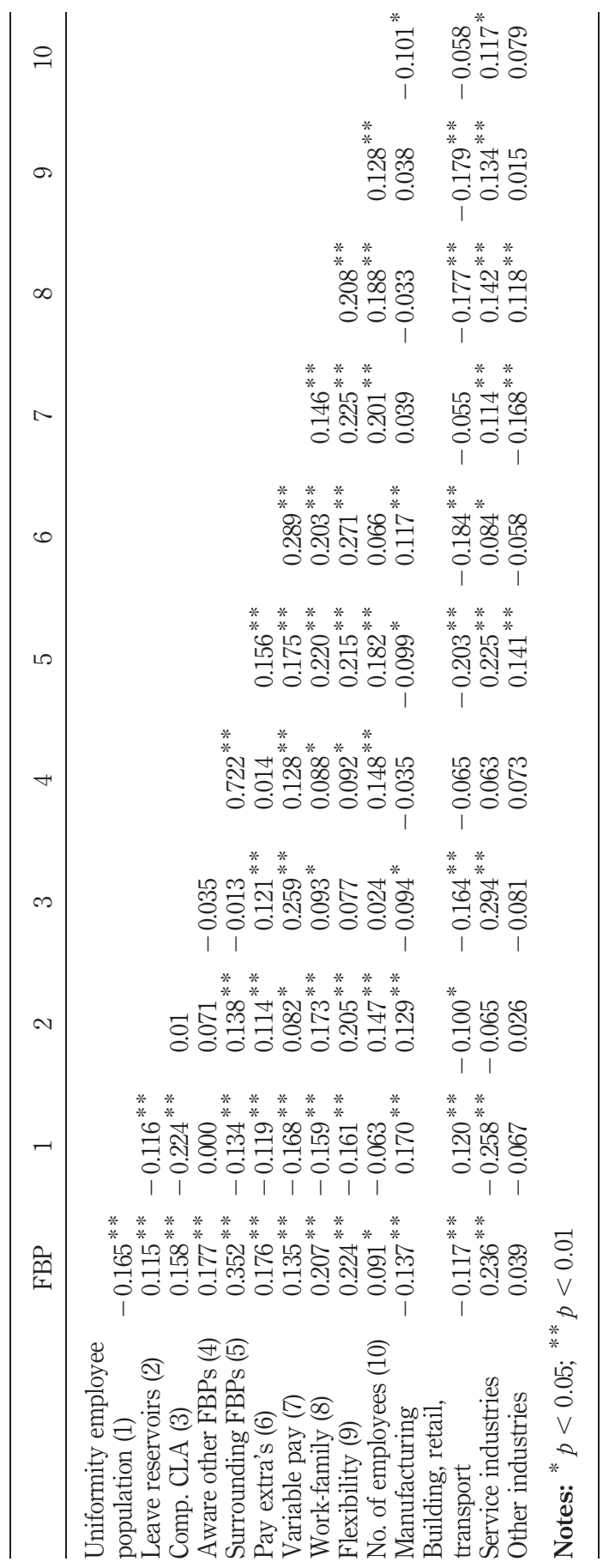


only managers or employees with a permanent contract could change their benefits. Of the organisations that had not introduced choice, 91 (27 per cent) said they were intending to do so. Four organisations that offered choice only to part of their employees were planning to expand it to all their employees. Of the organisations in our survey, 58 per cent (342) said they offered, or were about to offer, their employees an FBP. We focus on this group for our analyses, including the organisations where FBPs were still in a planning stage. In some cases it is known that these plans were very specific, in others plans may have been more vague. While there is something to be said for excluding them from our analyses, we nevertheless include them here, assuming that these organisations have made a definite decision to introduce a plan, and have therefore responded to the various pressures and considerations included in our model. The fact that most of them (72 of the 91) told us what goals and sources the plan would incorporate, supports this assumption.

Organisations were asked to name the sources and goals that employees could choose from. This way we discovered that there were 25 organisations that had said they had no choice model, but did offer their employees various options frequently seen in FBPs. If we include these organisations, the total of organisations that offers their employees some form of choice in their benefits is 62 per cent of the total.

Only 30.1 per cent of the organisations in the survey offered an FBP that included time and money as sources and goals, and 48.0 per cent of the organisations that offered some form of choice. Table II shows the choices that employees have in terms of time and money, as sources and goals, and the trades between these that they can make. Of the 25 organisations that offered various choices but claimed not to offer an FBP, eight met our definition of an FBP.

The option of trading in money for time off is the least common option employers offer. Time goals on the whole are rarer than financial goals. Employers seem more reluctant to allow employees to buy more time off, and reduce their working time than to offer them the reverse option. The goals outnumber the sources, though not in all individual cases. The average number of sources of all plans is 3.69 (SD 2.05), varying from zero to ten. The average number of goals is 4.32 (SD 2.5), varying from zero to 14 . The instances where people report zero goals or sources are organisations that are intending to introduce flexible benefits, but have not decided on the final set of goals and sources yet. Of the plans that fall within our definition, the averages are naturally higher and variation smaller: 4.66 sources (SD 1.73) and 5.56 goals (SD 2.32).

Table III contains an overview of specific sources and goals in FBPs. The majority of FBPs have salary, holiday money, holiday leave and overtime as sources, and an extra contribution to the pension plan, extra short-term or long-term leave, and

\begin{tabular}{lcc}
\hline & Of organisations with choice & Of all organisations \\
\hline Financial source & 82.3 & 51.6 \\
Time source & 81.2 & 50.9 \\
Financial goal & 90.7 & 56.9 \\
Time goal & 60.8 & 38.1 \\
Time $\rightarrow$ money & 79.3 & 49.7 \\
Money $\rightarrow$ time & 54.8 & 34.4 \\
FBP with trading time for money and vice versa & 48.0 & 30.1
\end{tabular}

\section{Offering choice in benefits}

315

Table II.

Time and money as sources and goals amongst organisations with some form of flexible benefits, either actual or planned $(n=367)$ and among all organisations $(n=585)$, in percentages 
IJM
29,4

\section{6}

\begin{tabular}{lllr}
\hline Sources & & Goals & \\
\hline Salary & 86.4 & Cash & 49.4 \\
End-of-year-payment & 47.2 & Savings account & 46.0 \\
Bonus & 35.8 & Extra contribution to pension & 76.1 \\
Profit sharing & 33.0 & Other financial goals & 5.1 \\
Holiday money & 59.7 & Short term leave & 63.6 \\
Other fin. sources & 14.2 & Long term leave, sabbatical & 62.5 \\
ADV hours & 52.3 & Study leave & 24.4 \\
Annual leave & 81.3 & Extension of parental leave & 21.6 \\
Overtime & 52.8 & Other leave-goal & 8.0 \\
Other sources & 6.3 & Reduction contr. childcare & 12.6 \\
& & Reduction contr. parental leave & 5.7 \\
& & Compensation travelling costs & 10.2 \\
& & Compensation study costs & 15.9 \\
& & Compensation PC & 80.7 \\
& & Compensation bike & 51.7 \\
& & Other compensations & 4.5 \\
& & Other goals & 8.0
\end{tabular}

Table III.

Sources and goals in FBPs, in percentages $(n=176)$
Notes: ${ }^{\mathrm{a}} \mathrm{ADV}$ hours are the free hours resulting from collective agreements on reduction of working hours, usually a couple of hours per week; ${ }^{\mathrm{b}}$ This saving arrangement allows employees to save out of financial sources before taxes

compensations for a PC and a bicycle (we are Dutch, after all) as goals. The "other" sources that were mentioned include compensation for being on call and the choice for a smaller lease car, after which the difference can be traded in for another benefit. Other goals include vegetable packages, discounts on the products of the organisation and mortgage payments.

Organisations that had already introduced an FBP were asked when they had done so. Figure 2 shows the number of FBPs introduced per year by organisations in our survey. There is a clear increase in new FBPs, with a peak in 2001, after which there is a distinct downturn. It will be interesting to see whether this downturn persists.

\section{Multivariate analysis}

Table IV shows the results of the multivariate binary logistic regression analysis of the theoretical model.

The variables of the business considerations segment of the model did not have any effect on the presence of an FBP. In fact, they can be removed without reducing the explanatory power of the model. A more uniform employee population does not increase the odds of an organisation offering an FBP[5], nor does the presence of many leave reservoirs amongst employees have an effect.

There was more effect from institutional surroundings. There is a strong effect from other organisations. Organisations that see many similar organisations offering FBPs have an FBP themselves more often than those that see few FBPs around them. This effect could work in both directions: the other organisations that people notice may be following the behaviour of the organisation in question, or the reverse could have happened, with the organisation following its surroundings. Whichever way around, there is a strong effect. Also, organisations that compose their own labour agreement 


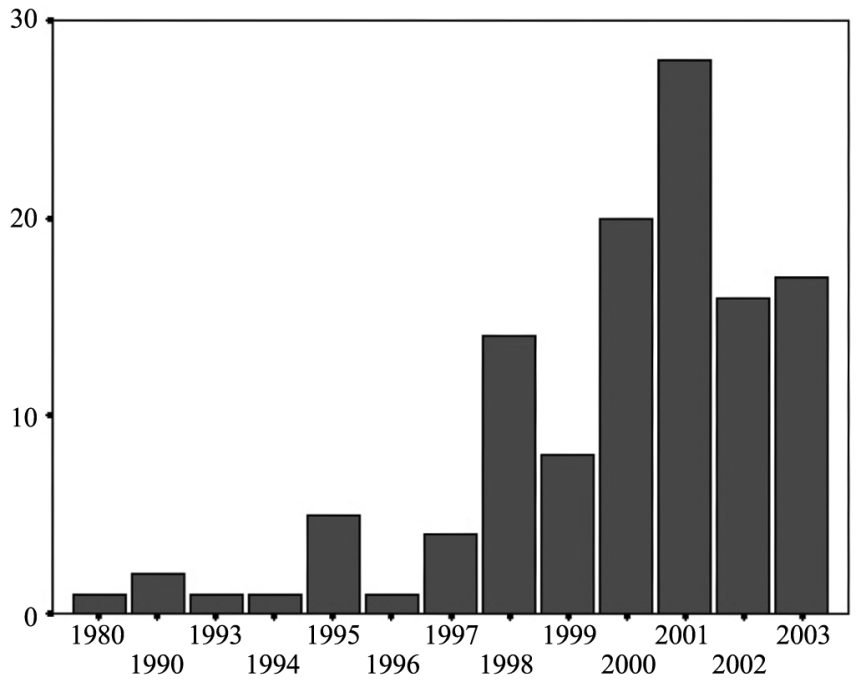

Offering choice
in benefits

317

Note: $\mathrm{N}=120$

Odds ratio

Business considerations

Uniformity employee population

0.988

Leave reservoirs ${ }^{\mathrm{a}}$

1.283

Institutional pressures

Company CLA ${ }^{\mathrm{a}}$

$1.810 * *$

Aware of FBPs in other organisations ${ }^{\mathrm{a}}$

0.727

Prevalence of FBPs in surrounding organisations

$1.545^{* *}$

Bundles of HRM

Number of extra pay options

1.269

Number of variable pay options

1.003

Number of work family arrangements

$1.158^{*}$

Number of flexible arrangements

$1.407^{* *}$

Controlling variables

Number of employees

Building/retail/transport industries ${ }^{\mathrm{b}}$

1.000

Service industries ${ }^{\mathrm{b}}$

1.559

1.956 *

Other industries ${ }^{\mathrm{b}}$

1.429

LR $\chi^{2}$

$116.57^{* *}$

Notes: ${ }^{\mathrm{a}}$ Dummy variable: yes $=1$, no $=0 .{ }^{\mathrm{b}}$ The reference category is manufacturing; ${ }^{*} p<0.05$; $* * p<0.01$

Table IV.

Binary logistic regression of factors influencing the odds of an organisation offering an $\operatorname{FBP}(n=571)$

have an FBP more frequently than those that are covered by an industry CLA. There is clearly a restrictive effect of industry CLAs, as we expected. Organisations that have room for manoeuvre in their benefits themselves pass on this favour to their employees. 
IJM

29,4

318
The bundles of HRM section of the model also shows several statistically significant results. FBPs become more likely as an organisation offers more flexibility in time and place, and more work-family arrangements. This last effect could have been caused by the fact that certain work-family arrangements are common elements of FBPs. This does not appear to be the case. There are numerous organisations that offer work-family arrangements that are not included in an FBP.

FBPs turn out to be complementary to flexible and family-friendly HRM, not to be a substitute for it. FBPs are also not used as a substitute for variable or extra pay arrangements. This means there may be a problem of endogeneity in the analysis, as a common factor may be causing both the occurrence of the arrangements in the bundles, and the occurrence of FBPs. Here one might think of a positive attitude towards flexibility in the organisation, the conviction that HRM policies aimed at supporting employees in their combination of work and care will help the organisation on the labour market, not just in attracting, but also in keeping the right staff, or a belief that giving employees the responsibility to arrange the fringe arrangements of their labour to their own liking will promote their flexibility within their tasks as well. Unfortunately our current data do not allow us to meaningfully test for such influences, as the attitudes regarding the effects of HRM arrangements were not properly addressed in the questionnaire that was used to collect these data.

Larger organisations do not choose more frequently for these plans than smaller organisation in the survey. There was evidence of industrial diversity: FBPs were more common in the service industries than in the manufacturing industry.

A log ratio test showed that the three-part model is indeed an improvement to a model that only contains the rational choice and institutional pressures variables $\left(\chi^{2}\right.$ 18.95, $p<0.01)$.

\section{Discussion}

FBPs have become a regular feature in Dutch organisations in the last decade. More than 60 per cent of the organisations in our survey allowed their employees some choice in the composition of the benefits, while half of those offered an elaborate plan with time and money as sources and goals, or were planning to introduce such a plan. Plans in which people could sell some of their leave were more common than plans that allowed employees to buy more time off. Organisations seem more comfortable with their employees extending their working time than with them reducing their time, even when this is compensated for out of their own wages. This puts some perspective on benefit choice as a work-family tool: as work-family arrangements are not always and automatically included in FBPs, the reconciliation of work and family life will continue to need special attention and often specific measures too.

Our study provides a unique insight into the kind of market sector organisation that offers its employees a choice in the composition of their benefits, something about which little was known. The theoretical model we developed for this study proved to be valuable. Adding the bundles of HRM segment to a model that presumes organisations to rationally act based on their internal situation and institutional surroundings that has been used to explain new HRM arrangements proved to be worthwhile, it enhanced the explanatory power of the model significantly.

There was little evidence of support for the business considerations part of the model. In our study, we found no evidence for organisations introducing FBPs out of 
cost or efficiency considerations. However, this may be attributable to the factors that we incorporated in our model, and in a next study this section could be operationalised in a better way. Labour market considerations are the most important factor missing from our analysis. Because of the turbulent changes in the Dutch labour market at the time of our study we were unable to include this element in our analyses. If this could meaningfully be included in a next study of this phenomenon, this may very well shed a different light on the factors at play.

Institutional pressures undeniably play a role in the occurrence of FBPs in Dutch organisations. There is evidence of FBPs occurring in concentrations: in certain industries, but also more often in each other's company. This evidence of an uneven spread of FBPs throughout the Dutch economy is also an interesting topic for further research and could be addressed in greater detail than we have been able to do here. Furthermore, our study was limited to the market sector. Future research might be able to incorporate the public sector in a meaningful and effective way, which will further enhance our understanding of the spread of FBPs throughout the Dutch economy. Given that the public sector is known to generally offer more elaborate benefits, such a study could also shed more light on the role played by they HRM context.

The fact that organisations are more likely to have an FBP if they see many FBPs around them suggests mimicking behaviour amongst organisations. Whether they look to other organisations to see what it entails to be a good employer, or whether they simply do not want to stand out as being the only employer not to offer an FBP on the labour market, this is also an interesting topic for further research. But it is clear that it matters what other organisations do in this respect.

We also found evidence of restricting institutional surroundings, through collective labour agreements. Trade union reservations about flexible benefits, and a greater ability to swiftly react to new developments lead to FBPs occurring in organisations that define their own terms of labour. It is also interesting to see that organisations that have such room to move themselves are more likely to give their employees similar opportunities.

FBPs occur in distinct HRM surroundings. Organisations that have invested in flexible HRM and work-family arrangements have chosen for FBPs more often, showing that FBPs are introduced to complement existing arrangements, not as a substitute to them. These results do raise the possibility of endogeneity in our analyses, for both the existing HRM structure and the choice to introduce an FBP may be caused by the same underlying factors. Our current data did not allow us to test for endogeneity in a meaningful manner, unfortunately, as they did not include measures of such underlying factors. Future research should make an effort to bring these underlying factors to light, looking at the attitudes in organisations regarding the usefulness of HRM arrangements, for instance, and the ways HRM budgets are allocated and spent.

However, our results can be taken as evidence that employers judge the usefulness of new arrangements in their organisation on the existing HRM surroundings in which it would function. But we think it may point to more than consistent HRM policies. We suspect that organisations have a distinct sense of self as an employer, and that this sense of self may be affecting their analysis of the costs and benefits of an FBP too. Organisations that find it important to be a flexible and family-friendly employer will judge an FBP more positively. The role played by other organisations will be related to
Offering choice in benefits

319 
IJM

29,4

320 this sense of self as well. We think the results of our study show that organisations act partly out of a vision of themselves as employers, and that this vision influences their perceptions of the opportunities of flexible benefits.

Based on these findings, it seems that "economic" considerations concerning diversity and leave reservoirs do not play a very big role in these kinds of organisations. Nevertheless, as an overarching view of organisational behaviour, the notion of goal-oriented behaviour does remain useful. In our model we viewed organisations as incorporating facts from all three sections into their analysis of whether an FBP plan would be useful for them. While we have shown that the things that they take into consideration turn out to have more to do with their institutional surroundings and HRM policies, there is no reason to believe that the way these factors are responded to is not rational, or economic. Fitting in with other organisations in terms of the benefits one offers may make perfect economic sense, for instance when the organisation is competing with these other organisations on a tight labour market. Organisations balance the costs and benefits of introducing a flexible benefit plan, though clearly these costs and benefits exist in a wide spectrum.

\section{Notes}

1. We use the term benefits to refer to the various elements that make up the reward employees receive for their labour. This includes both pecuniary and non-pecuniary elements, such as leave, pension and compensations. While flexible benefit plans focus on what in The Netherlands are commonly referred to as secondary benefits, they are not restricted to these, wages are commonly included.

2. Of course, few organisations can be considered to truly be a single actor the way a human being is. Organisations by default consist of groups of people, who may, individually, strive towards different goals, or disagree on how the goals of the organisation as a whole can best be realised. The process of how an organisation comes to decide on an FBP is very interesting, and useful to examine, but beyond the scope of the current study. For the moment we shall leave this internal decision making process as it is, and look only at its outcome, i.e. the decision for or against flexible benefits. We will therefore take "the employer" or "the organisation" as referring to the central leadership of the organisation, following Remery (1998).

3. We owe many thanks to Jan Dirk Vlasblom for his help in this process.

4. Bivariate analyses showed that while certain components of FBPs are very common, it is not the case that certain arrangements included in the bundles here automatically mean there is an FBP: for instance, while most FBPs include an PC arrangement (81 per cent), organisations offering a PC arrangement do by no means all offer an FBP (only 33 per cent of them, in fact).

5. The separate diversity measures on which the overall measure was constructed, similarly did not have an effect. And while one may wonder whether gender diversity may only have an effect if one looks at the percentage of women employed, a separate analysis revealed that this, too, was not the case.

\section{References}

Baaijens, C. (2006), “Arbeidstijden: tussen wens en werkelijkheid”, $\mathrm{PhD}$ thesis, Utrecht University, Utrecht.

Baron, J.N. and Kreps, D.M. (1999), Strategic Human Resources, Frameworks for General Managers, John Wiley \& Sons, New York, NY. 
Barringer, M.W. and Milkovich, G.T. (1998), "A theoretical exploration of the adoption and design of flexible benefits plans, a case of human resource innovation", Academy of Management Review, Vol. 23 No. 2, pp. 305-25.

Benders, J., Delsen, L. and Smits, J. (2006), "Bikes versus lease cars, the use of cafeteria systems in The Netherlands", International Journal of Human Resource Management, Vol. 17 No. 6, pp. 1115-28.

Delsen, L., Benders, J. and Smits, J. (2006), "Choices within collective labour agreements à la carte in The Netherlands", British Journal of Industrial Relations, Vol. 44 No. 1, pp. 51-72.

den Dulk, L. (2001), Work-Family Arrangements in Organisations; a Crossnational Study in The Netherlands, Italy, the United Kingdom and Sweden, Rozenberg Publishers, Amsterdam.

DiMaggio, P.J. and Powell, W.W. (1983), "The iron cage revisited: institutional isomorphism and collective rationality in organizational fields", American Sociological Review, Vol. 48 No. 2 , pp. $147-60$.

Goodstein, J.D. (1994), "Institutional pressures and strategic responsiveness", Academy of Management Journal, Vol. 37 No. 2, pp. 350-82.

Hewitt, Heijnis en Koelman (2003), Resultaten Flex-survey, Flexibele Employee Benefits 2003, Hewitt, Heijnis en Koelman, Amsterdam.

Hillebrink, C. (2006), Flexible Benefits in Dutch Organisations, Ridderprint, Ridderkerk.

Hillebrink, C., Schippers, J.J. and van Stigt, J. (2004), Keuzes in Arbeidsvoorwaarden; een Onderzoek onder Leden van FNV Bondgenoten naar CAO à la Carte, FNV Bondgenoten, Utrecht.

Ingram, P. and Simons, T. (1995), "Institutional and resource dependence determinants of responsiveness to work-family issues", Academy of Management Journal, Vol. 38 No. 5 , pp. $1466-82$.

Kirton, G. and Greene, A.M. (2005), The Dynamics of Managing Diversity, a Critical Approach, 2nd ed, Butterworth-Heinemann, Oxford.

Konrad, A.M., Prasad, P. and Pringle, J.K. (2006), Handbook of Workplace Diversity, Sage, London.

Korteweg, J.A.C., Tijdens, K.G. and de Winter, J.M. (2003), Keuzemogelijkheden in CAO's, Wat is het de Werknemer Waard?, OSA, Tilburg.

Kuiper, R. (2004), “De 25 Beste Werkgevers, Profit en Non-profit - December 2004”, Intermediar, Vol. 40 No. 53, pp. 34-41.

Langedijk, M.C. (2001), Flexibel Belonen: De Keuze voor Arbeidsvoorwaarden op Maat, Koninklijke van Gorcum, Assen.

Laursen, K. and Mahnke, V. (2001), "Knowledge strategies, firm types, and complementarity in human-resource practices", Journal of Management and Governance, Vol. 5 No. 1, pp. 1-27.

Meyer, J.W. and Rowan, B. (1977), "Institutionalized organizations: formal structure as myth and ceremony", American Journal of Sociology, Vol. 83 No. 2, pp. 340-63.

Oliver, C. (1991), "Strategic responses to institutional processes", Academy of Management Review, Vol. 16 No. 1, pp. 145-79.

Peters, P. and Batenburg, R. (2004), "De keuze van organisaties voor thuiswerken en formeel thuiswerkbeleid”, Tijdschrift voor Arbeidsvraagstukken, Vol. 20, pp. 32-45.

Remery, C. (1998), Effecten van Emancipatiegericht Personeelsbeleid, Ridderprint, Ridderkerk.

Remery, C., Schippers, J. and Doorne-Huiskes, A. (2003), "van Family-friendly policies in The Netherlands: the tripartite involvement”, Personnel Review, Vol. 32 No. 4, pp. 456-73.

Schrama, J.J.H. and van den Ameele, A.N. (2004), Arbeid en Zorg in CAO’s 2003, SZW, Den Haag.
Offering choice in benefits

321 
IJM

29,4

322
Scott, W.R. (2001), Institutions and Organizations, 2nd ed., Sage, Thousand Oaks, CA.

Staatscourant (2000), "Staatscourant Wet van 30 November 2000 tot Wijziging van Titel 7.10 (Arbeidsovereenkomst) van het Burgerlijk Wetboek met Betrekking tot Vakantie en Ouderschapsverlof", Nos 2000/545, pp. 1-5.

StvA (1999), Naar Arbeidsvoorwaarden op Maat, Stichting van de Arbeid, Den Haag.

StvA (2004), De CAO: Wat en Hoe, Stichting van de Arbeid, Den Haag.

Tolbert, P.S. and Zucker, L.G. (1983), "Institutional sources of change in the formal structure of organisations: the diffusion of civil service reform, 1880-1935”, Administrative Science Quarterly, Vol. 28 No. 1, pp. 22-39.

van der Burg, B.I., van Doorne-Huiskes, A., Schippers, J.J. and Siegers, J.J. (1989), "Loopbaanverschillen tussen Mannen en Vrouwen binnen Arbeidsorganisaties, een Structureel-individualistisch Verklaringsschema”, Sociologische Gids, Vol. 36, pp. 312-23.

van Drongelen, J. (2002), Teksten en Toelichting op de Wet Arbeid en Zorg, SDU Uitgevers, Den Haag.

van Sas, E. (forthcoming), "Decentralisatie en Individualisering in CAOs”, $\mathrm{PhD}$ thesis, Utrecht University, Utrecht.

van Sloten, G.C., Nauta, A. and Oeij, P.R.A. (2005), Arbeidsvoorwaarden en arbeidsverhoudingen op ondernemingsniveau; AVON monitor 2004, TNO Arbeid, Hoofddorp.

\section{About the authors}

Carlien Hillebrink worked as a PhD Candidate at the Utrecht School of Economics, part of Utrecht University. The topic of her $\mathrm{PhD}$ thesis concerned the occurrence of flexible benefit plans in Dutch organizations, and employee choices within such plans. The project was part of a larger research project on time competition and the combination of work and care, funded by the Netherlands Organisation for Scientific Research (NWO).

Joop Schippers is Professor of Labour Economics and the Economics of Equal Opportunity at Utrecht University. He is also one of the program directors of the Institute of Labour Studies (OSA) at Tilburg, and coordinates the research program Life courses, transitions and the combination of labour and care. His research interest includes male-female wage differences, human capital investments, labour market flexibility and organizational behaviour with respect to women and older workers. Joop Schippers is the corresponding author and can be contacted at: j.schippers@econ.uu.nl

Anneke van Doorne-Huiskes is Professor Emeritus of Sociology at the Department of Sociology and ICS Research School of Utrecht University. Her major interests lie in the areas of welfare states, labour market and gender, gender and organization, organizational culture and work-life balance.

Pascale Peters is Assistant Professor at the Nijmegen School of Management, Radboud University Nijmegen (PARTNER research group). Her research interests include work-life balance issues and flexible work arrangements, particularly home-based telework.

To purchase reprints of this article please e-mail: reprints@emeraldinsight.com Or visit our web site for further details: www.emeraldinsight.com/reprints 